\title{
EFEKTIFITAS FOOT CARE EDUCATION TERHADAP PRAKTIK PERAWATAN KAKI DALAM UPAYA PENCEGAHAN RISIKO ULKUS KAKI DIABETIK PADA PENDERITA DIABETES DI WILAYAH KABUPATEN KUNINGAN
}

\author{
Heri Hermansyah, Azis Setiawan, Yana Hendriana \\ Program Studi S1 Keperawatan Sekolah Tinggi Ilmu Kesehatan Kuningan Garawangi \\ herimj23@yahoo.com
}

\begin{abstract}
Abstrak
Kejadian ulkus kaki diabetik memiliki kecenderungan mengalami peningkatan seiring dengan meningkatnya diabetisi dan sering kali berakhir dengan kecacatan dan kematian. Kabupaten Kuningan menempatkan diabetes pada urutan pertama penyakit yang paling banyak menjalani perawatan inap di Rumah Sakit dengan jumlah kasus 968 penderita pada tahun 2015. Penelitian ini bertujuan untuk mengetahui efektifitas foot care education terhadap perbaikan praktik perawatan kaki dalam upaya pencegahan ulkus kaki diabetik pada diabetisi di Wilayah Kabupaten Kuningan. Penelitian ini menggunakan 2 jenis rancangan penelitian yakni cross sectional dan quasi experimental yang melibatkan 317 diabetisi (cross sectional) dan 220 diabetisi yang tidak pernah mendapatkan informasi tentang perawatan kaki (quasi experimental) sebagai sampel. Hasil penelitian ini adalah (1) status foot care education merupakan faktor yang memiliki hubungan yang signifikan dengan praktik perawatan kaki diabetisi dan perkembangan risiko ulkus kaki dengan p-value 0,01; 0,02 (Chi Square Test). (2) Terdapat perbedaan status praktik perawatan kaki yang signifikan antara kelompok intervensi dan kelompok kontrol pada posttest dengan $p$-value $0,000<\alpha 0,05$ (Mann Whitney $U$ Test). Dengan hasil ini, diharapkan pelayanan edukasi perawatan kaki pada tatanan pelayanan kesehatan dapat dioptimalkan guna meningkatkan praktik perawatan kaki oleh diabetisi untuk mencegah terjadinya komplikasi ulkus kaki terutama pada mereka yang berisiko tinggi.
\end{abstract}

Kata Kunci: Foot Care Education, Praktik Perawatan Kaki, Risiko Ulkus Kaki Diabetik

\section{Pendahuluan}

Penyakit neuropati merupakan salah satu komplikasi yang paling banyak ditimbulkan dari penyakit diabetes melitus (DM) yaitu sekitar 60\% dari komplikasi lainnya, dan $15 \%$ diantaranya menimbulkan ulkus kaki diabetik. Peningkatan prevalensi ulkus kaki diabetik sejalan dengan peningkatan jumlah penderita DM dan sering kali berakhir dengan kecacatan dan kematian. Diperkirakan sebesar 25\% penderita DM di
Indonesia mengalami ulkus kaki diabetik yang menyebabkan kejadian amputasi terbanyak yaitu sekitar $85 \%$ (Perkeni, 2009; Waspadji, 2009). Peningkatan terhadap kejadian diabetic foot ulcer dan amputasi secara tidak langsung dapat memperburuk keadaan sosial, ekonomi maupun psikologis penderita. Hal ini berhubungan dengan lama waktu perawatan yang dibutuhkan untuk proses penyembuhan ulkus diabetik yang pada akhirnya berdampak pada meningginya beban biaya perawatan bagi penderita dan keluarga. Meskipun kadangkala ulkus 
berhasil disembuhkan, hal tersebut tidak menjadikan penderita terbebas dari risiko kekambuhan. Sekitar 30-40\% penderita ulkus kaki diabetik yang berhasil disembuhkan mengalami kekambuhan pada tahun pertama kesembuhan. Sehingga keadaan tersebut akan lebih memperburuk kualitas hidup penderita (Iraj et al, 2013; Bus et al, 2013).

Mengingat dampak yang ditimbulkannya tersebut, maka diperlukan penanganan yang cermat terkait pencegahan terhadap risiko terjadinya ulkus kaki maupun amputasi pada penderita DM, yang salah satunya adalah patient education yang seharusnya menjadi poin utama dalam pengelolaan DM. Patient education bertujuan untuk mengubah perilaku dan mempromosikan self management penderita DM terhadap perubahan kondisi kesehatan yang dialaminya (Saurabh et al, 2014; Kurniawan \& Petpichetchian, 2011). Seperti pada penelitian Desalu et al (2011) dengan judul "Diabetic Foot Care: Self Reported Knowledge and Practice Among Patients Attending There Tertiary Hospitals in Nigeria" yang membuktikan bahwa mayoritas pasien dengan praktik perawatan kaki yang buruk memiliki pengetahuan mengenai perawatan kaki yang buruk pula yaitu sekitar 78,4\% . Sejalan dengan penelitian tersebut, Kurniawan \& Petpichetchian (2011) dalam penelitiannya memaparkan bahwa dengan adanya perbaikan terhadap perilaku penderita DM khususnya terkait perawatan kaki diharapkan dapat meminimalkan risiko terjadinya komplikasi ulkus kaki, amputasi, dan/atau kematian penderita.

Kabupaten Kuningan merupakan salah satu Kabupaten di Provinsi Jawa Barat Indonesia yang menempatkan DM pada urutan pertama penyakit yang paling banyak menjalani perawatan inap di Rumah Sakit dengan jumlah kasus 968 penderita pada sepanjang tahun 2015 silam, dengan 42 penderita diantaranya meninggal dunia akibat berbagai komplikasi yang ditimbulkannya yang salah satunya adalah ulkus kaki diabetik (Dinkes Kuningan, 2015).

Penelitian ini dilakukan dengan tujuan untuk mengetahui efektifitas foot care education terhadap perbaikan praktik perawatan kaki dalam upaya pencegahan ulkus kaki diabetik pada diabetisi di Wilayah Kabupaten Kuningan.

\section{Metode Penelitian}

Penelitian ini menggunakan 2 metode penelitian yakni observasional analitik "cross sectional" dan quasi experimental dengan rancangan pre-post test dengan 2 kelompok yang terdiri dari kelompok intervensi dan kelompok kontrol. sampel ditentukan dengan tehnik total sampling dimana kami melakukan survei pada seluruh diabetisi yang melakukan kunjungan rawat jalan di Poliklinik Penyakit Dalam RSUD 45 Kuningan selama bulan Juli 2018. Adapun jumlah diabetisi yang melakukan kunjungan rawat jalan selama bulan Juli 2018 adalah sebanyak 317 diabetisi. Dan 234 diantaranya merupakan pasien diabetisi yang belum pernah mendapatkan pelayanan foot care education selama menjalani perawatan yang kami gunakan sebagai sampel pada pre-post test. Akan tetapi dari 234 sampel tersebut terdapat 15 diabetisi yang mengundurkan diri dan tidak bersedia menjadi responden dalam penelitian ini. Sehingga total sampel untuk rancangan pre-post test terdapat 220 diabetisi yang dibagi menjadi 110 kelompok intervensi dan 110 lainnya menjadi kelompok kontrol.

Pengumpulan data dilakukan dengan menggunakan kuesioner praktik perawatan kaki yang diadaptasi dari kuesioner question determining the knowledge and practices about foot carequestion determining the knowledge and practices about foot care yang dikembangkan oleh Hasnain \& Sheikh pada tahun 2009, dan pemeriksaan kaki Inlow's 60 Second Diabetic Foot 
Screening Tool) yang disusun oleh Canadian Association of Wound Care untuk memperoleh data terkait risiko ulkus kaki diabetisi.

Pengisian kuesioner praktik perawatan kaki dilakukan 2 kali bagi yang termasuk ke dalam kelompok pre-post test. Penilaian kembali praktik perawatan kaki dilakukan pada kunjungan rawat jalan kedua dengan durasi 1 bulan setelah dilakukannya treatmen berupa foot care education pada kelompok intervensi.

Analisis data dilakukan dengan menggunakan SPSS dengan uji Chi Square untuk menentukan adanya hubungan antara foot care education dengan praktik perawatan kaki dan risiko ulkus kaki diabetik. Sedangkan untuk mengetahui efektifitas foot care education terhadap perbaikan praktik perawatan kaki, kami analisis dengan melakukan uji statistik Wilcoxon pada masing-masing kelompok yang berpasangan, dan uji Mann Whitney $U$ pada kelompok yang tidak berpasangan.

\section{Hasil Penelitian}

Tabel 1. Hubungan antara Foot Care Education dengan Praktik Perawatan Kaki dan Risiko Ulkus Kaki Diabetisi di Poliklinik Penyakit Dalam RSUD 45 Kuningan Kabupaten Kuningan Jawa Barat Bulan Juli 2018 (n=317)

\begin{tabular}{|c|c|c|c|c|c|c|}
\hline \multirow{3}{*}{\begin{tabular}{l}
\multicolumn{1}{c}{ Variabel } \\
Praktik \\
Perawatan kaki
\end{tabular}} & \multicolumn{4}{|c|}{ Foot Care Education } & \multirow[b]{2}{*}{$\begin{array}{l}\text { OR } \\
(95 \% \mathrm{CI})\end{array}$} & \multirow[b]{2}{*}{$p$-value } \\
\hline & \multicolumn{2}{|c|}{ Pernah } & \multicolumn{2}{|c|}{$\begin{array}{c}\text { Tidak } \\
\text { Pernah }\end{array}$} & & \\
\hline & $\mathbf{F}$ & $\%$ & $\mathbf{F}$ & $\%$ & & \\
\hline Baik & 46 & 14,5 & 92 & 29,0 & 1,91 & $001 *$ \\
\hline Kurang & 37 & 11,7 & 142 & 44,8 & $1,15-3,18$ & \\
\hline Total & 83 & 26,2 & 234 & 73,8 & & \\
\hline Risiko Ulkus Kaki & $\mathbf{F}$ & $\%$ & $\mathbf{F}$ & $\%$ & & \\
\hline Risiko Rendah & 47 & 14,8 & 99 & 31,2 & 1,78 & $00 \Omega$ * \\
\hline Risiko TInggi & 36 & 11,4 & 135 & 42,6 & $1,07-2,95$ & $0,02^{*}$ \\
\hline Total & 83 & 26.2 & 234 & 73,8 & & \\
\hline
\end{tabular}

*Bermakna pada $\alpha: 0,05$

\section{Gambaran Foot Care Education, Praktik Perawatan Kaki dan Risiko Ulkus Kaki}

317 diabetisi dilibatkan dalam penelitian ini. Terdapat lebih dari setengahnya yakni 234 diabtetisi $(73,8 \%)$ tidak pernah mendapatkan pelayanan foot care education dari petugas pelayanan kesehatan selama menjalani perawatan. Sebagian besar diabetisi memiliki status praktik perawatan kaki yang kurang baik $(56,5 \%)$. Dan sekitar $54 \%$ diabetisi berisiko tinggi mengalami ulkus kaki diabetik.

\section{Hubungan antara Foot Care Education dengan Prakti Perawatan Kaki dan Risiko Ulkus Kaki}

Status foot care education diabetisi merupakan faktor yang memiliki hubungan yang signifikan dengan praktik perawatan kaki ( $p$-value 0,01) dan perkembangan risiko ulkus kaki ( $p$-value 0,02) yang dianalisis dengan uji Chi Square. Hasil ini dapat dilihat pada tabel berikut ini: 


\section{Pengaruh Foot Care Education Terhadap Praktik Perawatan Kaki}

Hasil uji Wilcoxon (Tabel 2) pada kelompok intervensi dan kontrol didapatkan $p$-value pada masing-masing kelompok sebesar 0,000 dan 0,074. Dengan demikian dapat disimpulkan bahwa terdapat perbedaan yang signifikan antara status praktik perawatan kaki pretest dan posttest pada kelompok intervensi dengan $p$-value $0,000<\alpha 0,05$. Sedangkan pada kelompok kontrol tidak ada perbedaan yang signifikan dari status praktik perawatan kaki pada pretest maupun posttest dengan $p$-value $0,074>\alpha$
0,05. Pada uji Mann Whitney $U$ (Tabel 3) didapatkan bahwa terdapat perbedaan status paraktik perawatan kaki yang signifikan antara kelompok intervensi dan kelompok kontrol pada posttest dengan $p$ value $0,000<\alpha 0,05$.

Dengan demikian dapat disimpulkan bahwa pemberian pelayanan foot care education pada diabetisi cukup efektif dalam meningkatkan praktik perawatan kaki oleh diabetisi. Dengan praktik perawatan kaki yang baik, diharapkan dapat mencegah terjadinya ulkus kaki pada diabetisi terutama pada mereka yang berisiko tinggi.

Tabel 2. Perbandingan Status Perawatan Kaki Sebelum dan Sesudah diberikan Pelayanan Foot Care Education dengan Uji Wilcoxon (Kelompok Intervensi n=110; Kelompok Kontrol $n=110$ )

\begin{tabular}{|c|c|c|c|c|c|c|}
\hline $\begin{array}{c}\text { Status Praktik } \\
\text { Perawatan Kaki }\end{array}$ & $\mathbf{F}$ & $\%$ & Mean & \multicolumn{2}{|c|}{ Rank } & $p$-value \\
\hline \multicolumn{7}{|l|}{ Kelompok Intervensi } \\
\hline Pre test & & & 1,39 & & & \\
\hline Baik & 43 & 60,9 & & Negatif & 2 & \\
\hline Kurang & 67 & 39,1 & & Positif & 54 & $0,000 *$ \\
\hline Post test & & & 1,86 & Ties & 54 & \\
\hline Baik & 95 & 86,4 & & & & \\
\hline Kurang & 15 & 13,6 & & & & \\
\hline \multicolumn{7}{|l|}{ Kelompok Kontrol } \\
\hline Pre test & & & 1,40 & & & \\
\hline Baik & 44 & 40,0 & & Negatif & 14 & \\
\hline Kurang & 66 & 60,0 & & Positif & 6 & 0,074 \\
\hline Post test & & & 1,33 & Ties & 90 & \\
\hline Baik & 36 & 32,7 & & & & \\
\hline Kurang & 74 & 67,3 & & & & \\
\hline
\end{tabular}

*Bermakna pada $\alpha$ : 0,05

Tabel 3. Hasil uji Mann Whitney $U$, Perbedaan Status Praktik Perawatan Kaki Pretest dan Posttest pada Kelompok Intervensi $(n=110)$ dan Kontrol $(\mathbf{n}=110)$

\begin{tabular}{|c|c|c|c|c|c|c|}
\hline \multirow{2}{*}{ Kelompok } & \multicolumn{3}{|c|}{ Pretest } & \multicolumn{3}{|c|}{ Posttest } \\
\hline & $\mathbf{N}$ & Nilai $Z$ & p-value & $\mathbf{N}$ & Nilai $Z$ & p-value \\
\hline Intervensi & 110 & \multirow{2}{*}{$-0,138$} & \multirow{2}{*}{0,891} & 110 & \multirow{2}{*}{$-8,086$} & \multirow{2}{*}{$0,000 *$} \\
\hline Kontrol & 110 & & & 110 & & \\
\hline
\end{tabular}

*Bermakna pada $\alpha$ : 0,05 
JURNAL ILMU KESEHATAN BHAKTI HUSADA:

HeALTH SCIENCES JOURNAL, Vol. 09 No. 02, DESEMBER 2018

DOI: https://doi.org/10.34305/jikbh.v9i2.61 diharapkan dapat meningkatkan praktik perawatan kaki sehingga besarnya risiko ulkus kaki pada diabetisi dapat dicegah. Seperti halnya yang telah disampaikan oleh American Diabetic Association (2016) bahwa komplikasi kaki diabetik dapat dicegah dan dikurangi sebesar 50\% dengan perawatan kaki yang baik.

Oleh karenanya faktor terpenting dalam upaya pencegahan kejadian ulkus kaki diabetik yang sesungguhnya adalah dengan memberdayakan diabetisi dengan cara meningkatkan pengetahuan tentang perawatan kaki melalui pelayanan foot care education secara konsisten oleh penyedia layanan kesehatan.

Penelitian ini juga menemukan hasil bahwa melalui program pelayanan foot care education dapat meningkatkan praktik perawatan kaki yang lebih baik pada diabetisi.

Hasil tersebut relevan dengan unggkapan Notoatmodjo (2010) bahwa dengan adanya pendidikan kesehatan dapat meningkatkan pengetahuan dan sikap, perilaku, serta peningkatan status kesehatan seseorang. Black \& Hawks (2009) juga berpendapat hal yang sama dimana dengan adanya program pelayanan pendidikan kesehatan tentang perawatan kaki diharapkan terjadi perubahan perilaku diabetisi yang lebih konstruktif untuk meningkatkan kemampuannya dalam mengelola kesehatannya sendiri termasuk mengontrol dan mencegah terjadinya komplikasi ulkus kaki melalui praktik perawatan kaki yang optimal.

Dengan adanya program edukasi perawatan kaki yang tepat oleh penyedia layanan kesehatan diharapkan mampu untuk mencegah dan memutus risiko terjadinya ulkus kaki pada diabetisi. seperti halnya yang dikemukan oleh Ren et al (2014) dalam penelitiannya yang berjudul "Effect of Intensive Nursing Education on the Prevention of Diabetic Foot Ulceration Among Patients with High-Risk Diabetic Foot: A Follow-Up Analysis" bahwa pendidikan kesehatan secara intensif dapat membantu diabetisi untuk lebih aktif dalam mengelola kesehatannya dan ini bermanfaat dalam 
JURNAL ILMU KESEHATAN BHAKTI HUSADA:

HeALTH SCIENCES JOURNAL, Vol. 09 No. 02, DESEMBER 2018

DOI: https://doi.org/10.34305/jikbh.v9i2.61

pencegahan dan penyembuhan faktor risiko penyakit kaki diabetik terutama bagi mereka yang memiliki risiko tinggi.

\section{Kesimpulan}

Penelitian ini menemukan bahwa foot care education cukup efektif untuk memperbaiki praktik perawatan kaki dalam upaya pencegahan risiko ulkus kaki diabetik pada penderita diabetes. Hal ini dikarenakan adanya hubungan yang erat antara foot care education dengan praktik perawatan kaki dan risiko ulkus kaki.

\section{Saran}

Dengan adanya temuan hasil penelitian ini dapat dijadikan bahan kajian bagi penyedia layanan kesehatan khususnya pelayanan keperawatan untuk secara konsisten memberikan pelayanan edukasi tentang perawatan kaki pada penderita diabetes.

\section{Daftar Referensi}

American Diabetes Association. (2016). Standards of Medical Care in Diabetes. USA: The Journal of Clinical and Applied Research and Education, Vol 39 (1).

Black Joyce \& Hawks, Jane Hokanson. (2009). Medical Surgical Nursing: Clinical Management for Positive Outcomes. Saunders: Elsevier.

Bus, SA et al. (2013). Effect of Custommade Footwear on Foot Ulcer Recurrence in Diabetes: A Multicenter Randomized Controlled Trial. Diabetes Care. Vol 36: pp 4109-4116.

Deepa, LN et al. (2017). Assessment of Awareness and Practice Of Foot Care and Physical Activity Among People With Type 2 Diabetes Attending a Tertiary Care Teaching Hospital. International Journal of
Community Medicine and Public Health. Vol 4(9): pp 3218-3223.

Desalu, O et al. (2011). Diabetic Foot Care: Self Reported Knowledge and Practice Among Patients Attending Theree Tertiary Hospitals in Nigeria. Ghana Medical Journal. Vol 45(2): pp 60-65.

Dinas Kesehatan Kabupaten Kuningan. (2015). Profil Kesehatan Kabupaten Kuningan Tahun 2015. Kuningan: Dinas Kesehatan Kabupaten Kuningan.

Hasnain, S \& Sheikh, HS. (2009). Knowledge and Practices Regarding Foot Care in Diabetic Patients Visiting Diabetic Clinic in Jinnah Hospital Lahore. Journal Pakistan Medical Association. Vol 59 (10): pp 659-687.

Iraj, Bijan et al. (2013). Prevention of Diabetic Foot Ulcer. International Journal of Preventive Medicine. Vol 4 (3): pp 373-376.

Kurniawan, T \& Petpichetchian, W. (2011). Case Study: Evidence-based Interventions Enchancing Diabetic Foot Care Behaviours Among Hospitalized DM Patients. Nurse Media Journal of Nursing. Vol 1: pp 43-45.

Notoatmodjo, S. (2010). Ilmu Perilaku Kesehatan. Jakarta: Rineka Cipta.

Perkeni. (2009). Hubungan Pengetahuan dan Sikap Klien dengan Diabetes Melitus Tipe 2 Tahun 2009. Jakarta: Perkeni.

Ren, M et al. (2014). Effect of Intensive Nursing Education on the Prevention of Diabetic Foot Ulceration Among Patients with High-Risk Diabetic Foot: A Follow-Up Analysis. PubMed. Vol 16 (9): 576-581.

Robles R, Bohorquez et al. 2017. Knowledge and Practices of Diabetes Foot Care and Risk of Developing Foot Ulcers in México May Have Implications for Patients of Méxican Heritage Living in the US. PudMed. Vol 43 (3): pp 297-303. 
JURNAL ILMU KESEHATAN BHAKTI HUSADA:

HeALTH SCIENCES JOURNAL, Vol. 09 No. 02, DESEMBER 2018

DOI: https://doi.org/10.34305/jikbh.v9i2.61
Ciptaan disebarluaskan di bawah Lisensi Creative Commons Atribusi-

NonKomersial-BerbagiSerupa 4.0

Internasional.

Waspadji, S. (2009). Diabetes Melitus, Penyulit Kronik dan Pencegahannya. Jakarta: Balai Penerbit FKUI. Among People with Type 2 Diabetes in Rural Puducherry, India. Indian Journal of Endocrinology and Metabolism. Vol 18 (1): pp 106-110. 